\title{
NOVAS PERSPECTIVAS DE ENSINO DE INGLÊS: RECONHECENDO AS VARIEDADES LINGUÍSTICAS NA COMUNICAÇÃO ORAL
}

\author{
Eduarda Hackenhaar ${ }^{1}$ \\ Maristela Juchum ${ }^{2}$
}

\begin{abstract}
Resumo: A presença da língua inglesa é constante no dia a dia dos estudantes brasileiros, ultrapassando os limites da sala de aula. Na grande maioria das vezes, no entanto, o inglês conhecido por esse público é aquele pertencente ao falante nativo norte-americano. Com este trabalho, buscou-se descobrir as percepçóes de estudantes do Ensino Médio, que frequentam uma Escola de Idiomas, acerca de variações orais de falantes de inglês de países distintos. Para tal, uma intervenção pedagógica foi aplicada com o público-alvo. Os resultados evidenciaram que as variedades estadunidense e britânica da língua foram as preferidas pelos alunos que as classificaram com adjetivos como melhor, bonita e padrão. Por outro lado, o inglês dos indivíduos da Colômbia, Índia e África do Sul foi pouco compreensível e imediatamente relacionado a aprendizes do idioma. Pode-se perceber que os alunos demonstraram interesse em conhecer mais sobre falantes de inglês ao redor do mundo, o que não é oportunizado nas escolas, uma vez que o ensino da língua ainda é comumente orientado pela variedade estadunidense soberana. Como conclusão, enfatiza-se a necessidade de haver mudanças nas aulas de inglês para retratar as variedades dos falantes, culturas e países deste mundo globalizado e diversificado.
\end{abstract}

Palavras-chave: Variedades linguísticas. Sotaques. Inglês. Ensino.

\section{NEW ENGLISH TEACHING PERSPECTIVES: RECOGNIZING THE LANGUAGE VARIETIES IN ORAL COMMUNICATION}

Abstract: The presence of the English language in the daily lives of Brazilian students is constant, exceeding the limits of the classroom. Most of the time, however, the English known to this audience belongs to the Native American speaker. With this work, it was aimed to discover the perceptions of

1 Graduanda do curso de Letras Português/Inglês pela Universidade do Vale do Taquari - Univates, eduarda.hackenhaar@universo.univates.br

2 Doutora em Letras com especialidade em Linguística Aplicada e docente na Universidade do Vale do Taquari - Univates, juchum@univates.br 
high school students, who attend a Language School, regarding oral variations of English speakers from different countries. To this end, a pedagogical intervention was applied with the target audience. The results have demonstrated that the American and British varieties of the language were preferred by the students who classified them with adjectives as better, beautiful, and standard. On the other hand, the English of individuals from Colombia, India, and South Africa was poorly understood and immediately related to language learners. It was possible to notice that the students showed interest in knowing more about English speakers around the world, which is not provided by schools since the teaching of the language is still commonly guided by the sovereign American variety. In conclusion, it emphasizes the need for changes in English classes to portray the varieties of speakers, cultures, and countries in this globalized and diverse world.

Keywords: Linguistic varieties. Accents. English. Teaching.

\section{CONSIDERAÇÓES INICIAIS}

Os jovens brasileiros estão em constante contato com uma língua que não é a sua materna: o inglês - na escola, obrigatoriamente a partir do sexto ano do Ensino Fundamental, conforme regulamentado pela Base Nacional Comum Curricular (BRASIL, 2018), e nos momentos de lazer, através de músicas, filmes e séries estrangeiros. O que é fato desconhecido de muitos é que o inglês majoritariamente difundido, vendido e consumido pelos estudantes, independentemente do contexto, é a variante proveniente dos Estados Unidos, uma vez que o conteúdo exportado em massa provém de tal país.

O falante nativo norte-americano tem sido apresentado repetidamente como um modelo a ser seguido ao se expressar na língua, cuja versão - ao não ser reproduzida - coloca em risco o falar bem a língua (ANJOS, 2019). Além disso, o ensino do inglês norte-americano priva os estudantes de (re)conhecerem outras variantes orais da língua inglesa, como a indiana, a sul-africana e a chilena. Com isso, questiona-se: quais são as percepções dos alunos referente às variedades linguísticas de falantes de língua inglesa ao redor do mundo?

Esta pesquisa tem por objetivo analisar as impressôes de estudantes de uma Escola de Idiomas, do município de Venâncio Aires/RS, a fim de verificar se os discentes conhecem outras variedades linguísticas além da pronúncia do inglês estadunidense, predominantemente utilizada no ensino do idioma. Os objetivos específicos são (1) apresentar, aos alunos, falantes e sotaques distintos de língua inglesa, (2) proporcionar reflexóes acerca do ensino de língua inglesa no Brasil, e (3) contribuir para a formação de novas perspectivas de ensino de inglês apoiando-se no conceito de língua franca.

Por meio de uma intervenção pedagógica, foram apresentados ao públicoalvo mencionado demais falantes de inglês que não fossem da variedade soberana da língua. Desse modo, oportunizaram-se aos alunos diferentes formas de aprendizagem da língua inglesa, sem se limitar a apenas uma variedade linguística. Sendo assim, este estudo justifica-se pela necessidade de propagar novas metodologias de ensino descentralizadas do falante norte-americano nativo. 
O presente artigo está organizado de modo a expor, primeiramente, as seçôes de referencial teórico, evidenciando pressupostos teóricos que norteiam o tema, tendo como base uma perspectiva sociolinguística de língua. Em seguida, é relatada, em detalhes, a metodologia utilizada para a pesquisa, tanto do planejamento quanto da aplicação da intervenção pedagógica. Por fim, os resultados são exibidos após a realização do trabalho, refletindo-se acerca das conclusóes e respostas alcançadas.

\section{O INGLÊS NO MUNDO}

A língua inglesa é o idioma oficial de comunicação em mais de sessenta países, mas sua utilização não se limita a apenas tais nações. Atualmente, o inglês possui mais falantes fora dos países mencionados do que dentro deles, isto é, a quantidade de estrangeiros que aprendem o inglês é muito superior àqueles que a adquirem como língua materna. De acordo com The World Economic Forum ${ }^{3}$, cerca de 1,5 bilhão de pessoas falam inglês ao redor do mundo, enquanto menos de 400 milhóes a possuem como primeira língua (L1).

$\mathrm{Na}$ imagem 1, é possível perceber os países destacados em que a língua oficial é a inglesa. Todavia, vale ressaltar que nem todas as naçôes que adotam o inglês como idioma oficial a utilizam como o principal meio de comunicaçáo no dia a dia. Messias (2015) aponta que esses países são divididos segundo as expressóes latinas "de facto" e "de jure" para separar aqueles que a têm como língua oficial na teoria ou pela lei, respectivamente. O autor complementa que "os países com adoção de 'facto + jure' são somente Estados Unidos, Reino Unido e Nova Zelândia. Todos os demais são apenas 'de jure'” (MESSIAS, 2015, p. 224), como é o caso da Índia e do Paquistáo.

3 LUSTIG, Robin. 2018. Can English remain the 'world's favourite' language? Disponível em: <https://www.bbc.com/news/world-44200901>. Acesso em: 08 out. 2020. 
Imagem 1. Países com falantes de inglês.

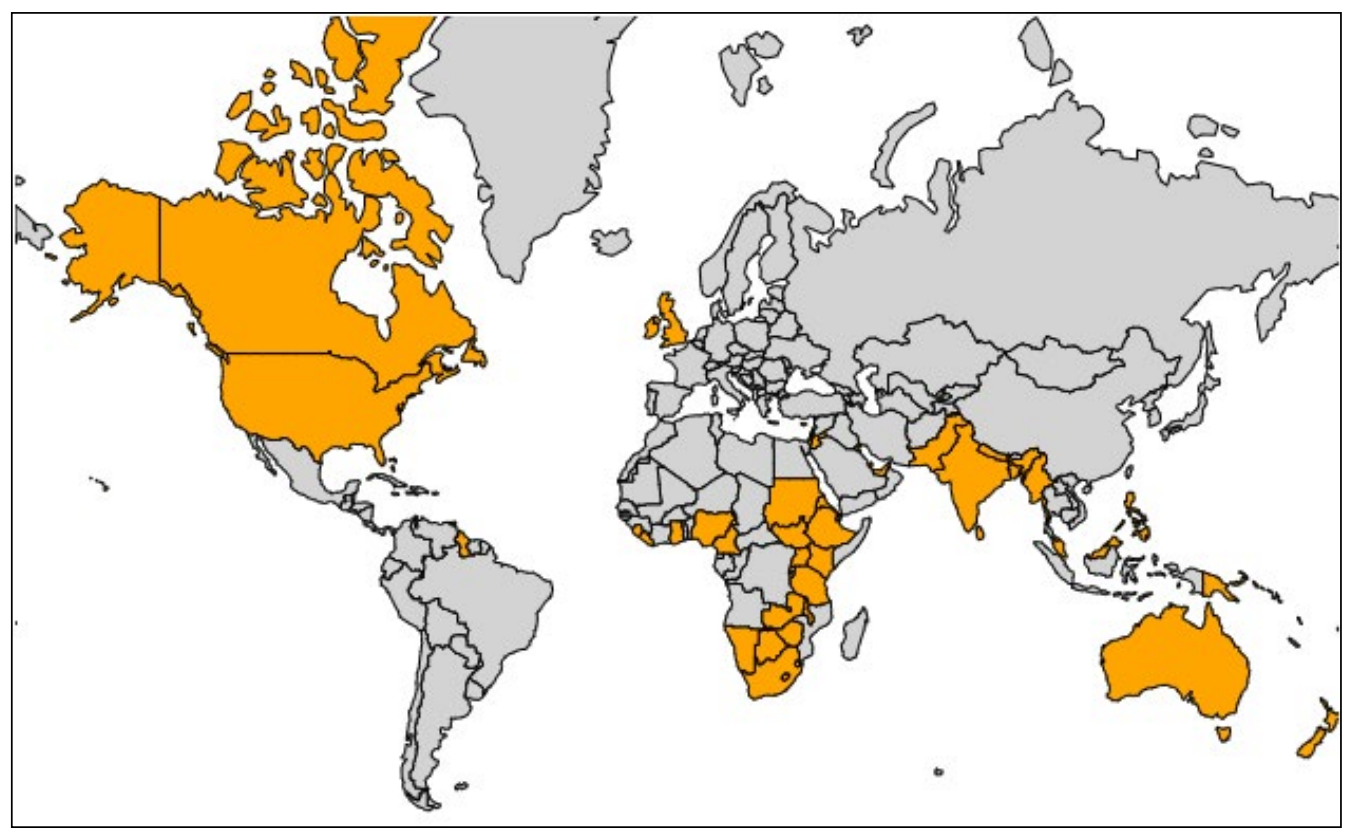

Fonte: World Population Review ${ }^{4}$

Devido à crescente globalização que estamos enfrentando, saber inglês tornou-se uma necessidade. Além de ser um conhecimento valorizado para o mercado de trabalho, por exemplo, a língua é também essencial para atividades culturais e cotidianas. Conforme Cabral $(2014$, p. 1), "o idioma é a língua oficial da Informática, do cinema mundial, dos desportos internacionais, da aviação, dos encontros científicos, do comércio internacional e do turismo". Dessa forma, pode-se afirmar que o inglês é a língua da comunicação mundial e o veículo de intercâmbio cultural.

Sabendo que o inglês é um idioma desterritorializado e sem fronteiras, não é novidade que ele seja o principal meio de comunicação nos mais diversos encontros pelo mundo. Cogo (2012 apud ANJOS, 2019) pontua que esses eventos podem ocorrer na internet, no Facebook, num escritório em Beijing, numa palestra universitária, em Amsterdam, numa barraca de mercado, em Marrakesh, num bar em Miláo e em um abrigo em São Paulo. Assim, o que se tem observado é que pessoas de diferentes nacionalidades têm escolhido, cada vez mais, o inglês como alternativa de comunicaçáo (ANJOS, 2019, p. 59).

4 WORLD POPULATION REVIEW. English Speaking Countries 2020. Disponível em: $<$ https://worldpopulationreview.com/country-rankings/english-speaking-countries>. Acesso em: 08 out. 2020. 
Uma vez que a língua é usada em larga escala e envolve povos de diferentes nacionalidades e culturas, o inglês prevalece como uma língua franca (ILF) frequentemente representada com o acrônimo ELF (English as a Lingua Franca). Jenkins (2000) indica várias vantagens ao adotar-se esse conceito de língua.

ILF enfatiza o papel do inglês na comunicação entre falantes de diferentes L1s, isto é, o principal motivo para aprender inglês hoje em dia; sugere a ideia de comunidade em oposição ao estrangeiro; enfatiza que as pessoas têm algo em comum ao invés de suas diferenças; implica que 'misturar' línguas é aceitável (que era, de fato, o que as linguas francas originais faziam) e, portanto, que não há nada inerentemente errado em reter certas características da L1, como o sotaque; finalmente, o nome latino remove simbolicamente a propriedade do inglês dos Anglos para ninguém e, na realidade, para todos. Todos esses resultados são altamente apropriados para um idioma que desempenha uma função internacional. ${ }^{5}$ (JENKINS, 2000, p.11, tradução nossa)

De mesmo modo, Gimenez et al. (2015, p. 603) caracterizam a língua inglesa franca como fluida, dinâmica e híbrida, retirando do falante a responsabilidade de seguir rótulos para haver a comunicação eficaz. Parafraseando os autores, o ILF não é uma variante única, já que ela acolhe falantes de inglês independente de suas L1 e reconhece seu caráter pluricêntrico, sem impor normas ou modelos de reprodução.

\section{O USO DA LÍNGUA EM SOCIEDADE}

A língua, seja ela qual for, é o meio utilizado pelo homem - um ser social - para comunicar suas ideias. Reforçando a relação de língua e sociedade, Messias (2015) assegura que ela é encarada como um fenômeno essencialmente social e dinâmico, pelo fato de estar ligada à sociedade e, por conseguinte, às pessoas que dela se valem em suas relaçóes sociais, culturais, pessoais, familiares e profissionais. Já que a ciência que se ocupa de estudar a língua em situaçôes reais de uso é a sociolinguística, os pressupostos teóricos e as reflexôes aqui expostas orientam-se na visão sociolinguística de língua e sociedade.

Considerando, portanto, a língua como uma instituição social, torna-se impossível estudá-la como uma estrutura autônoma (UFSM, texto digital), ou seja, os aspectos sociais e culturais não podem ser separados. Dessa maneira, havendo seres repletos de cultura própria, reflexo da sociedade em que estáo inseridos, a língua acaba por sofrer variaçôes a depender do indivíduo que a utiliza.

Qualquer língua, falada por qualquer comunidade, exibe sempre variaçóes. Nenhuma língua apresenta-se como entidade homogênea. Todas são

5 ELF emphasizes the role of English in communication between speakers from different L1s, i.e. the primary reason for learning English today; it suggests the idea of community as opposed to alienness; it emphasizes that people have something in common rather than their differences; it implies that 'mixing' languages is acceptable (which was, in fact, what the original lingua francas did) and thus that there is nothing inherently wrong in retaining certain characteristics of the L1, such as accent; finally, the Latin name symbolically removes the ownership of English from the Anglos both to no one and, in effect, to everyone. 
representadas por um conjunto de variedades. Língua e variação são inseparáveis: a Sociolingüística encara a diversidade da lingüística não como um problema, mas como qualidade constitutiva do fenômeno linguístico. (UFSM, texto digital, p.13)

De acordo com o material eletrônico da disciplina de Sociolinguística, da Universidade Federal de Santa Maria - UFSM (texto digital), o objeto de estudo da sociolinguística sáo as diversidades linguísticas manifestadas verbalmente. "A variação, portanto, não é vista como um efeito do acaso, mas como um fenômeno cultural motivado por fatores lingüísticos e por fatores extralingüísticos de vários tipos" (UFSM, texto digital, p. 08), como classe social, idade, sexo, região e contexto geográfico. Assim, é possível que os falantes de uma mesma língua se expressem com diferentes expressóes, pronúncias e sotaques por inúmeros motivos.

A língua inglesa, assim como todas as outras, possui variantes sociais e regionais dentro de sua esfera de uso, seja essa um país, estado, cidade ou grupo de pessoas. Messias (2015) exemplifica alguns dos sistemas nos quais as variedades podem ser observadas: no léxico, na sintaxe e na pronúncia. Como esta pesquisa se interessa em falantes de inglês, a variação no sistema sonoro entre pessoas de diferentes países será observada e estudada única e exclusivamente.

Jenkins (2009) faz uso do termo World Englishes (WE) - Ingleses Mundiais, em tradução livre, - para se referir a todas as variedades de inglês, optando, assim, por pluralizar a palavra inglês. Segundo a autora, sob a vista de WE, todos ingleses "são variedades genuínas da língua, independentemente de serem ou não considerados 'padrão', 'qualificados' e como ou quem seus falantes são"6 (JENKINS, 2009, p. 200, tradução nossa). Dessa maneira, essa interpretaçáo valoriza todos os tipos de falantes, tal como o ILF, sem distingui-los - diferentemente do que as instituiçóes governamentais, os gramáticos prescritivos, os materiais didáticos e o público em geral tendem a fazer.

\section{METODOLOGIA}

A página da internet IDEA - International Dialects of English Archive (Arquivo de Dialetos Internacionais do Inglês) - é um recurso de consulta e pesquisa gratuito para o público interessado e engajado na temática de variedades orais de inglês. No site, é possível encontrar áudios gravados por pessoas de inúmeras nacionalidades, junto de informaçôes biográficas dos falantes. Dessa forma, seis áudios foram selecionados para serem reproduzidos ao público alvo investigado estudantes do Ensino Médio, de faixa etária 15 a 18 anos, que fazem aulas de inglês há dois anos em uma Escola de Idiomas do município de Venâncio Aires/RS considerando o perfil dos indivíduos e o foco da pesquisa.

6 All, according to this interpretation, are bona fide varieties of English regardless of whether or not they are considered to be 'standard', 'educated', and the like, or who their speakers are. 
Os falantes de inglês selecionados da plataforma IDEA foram: um homem de 18 anos morador da Flórida, nos Estados Unidos; uma mulher de 21 anos da Inglaterra; um homem de 31 anos, natural de Hyderabad na Índia; uma mulher de 39 anos de Bogotá, na Colômbia; um homem de 40 anos de Gana, na África; e, finalmente, uma mulher brasileira de 33 anos. Ressalta-se que todos possuem um alto nível de educação e também de domínio no idioma.

Todos os sujeitos que submeteram seus áudios ao site fizeram a leitura de uma mesma história, "Comma gets a cure" (anexo A), o que contribui para os entrevistados identificarem as diferenças na pronúncia dos mesmos vocábulos. Além disso, foi elaborada uma folha contendo perguntas norteadoras (anexo B) para que os estudantes investigados pudessem exprimir suas impressóes durante a aplicaçáo da intervenção pedagógica.

O primeiro dos questionamentos visa a descobrir observaçóes mais gerais sobre o sotaque dos falantes enquanto os áudios são reproduzidos. Após, há perguntas específicas sobre qual variedade oral os alunos gostariam de falar e com qual delas eles possuem mais contato no dia a dia. Para tanto, o público-alvo deve tentar identificar a nacionalidade de cada um dos falantes. Na sequência, deve-se apresentar o áudio de um sujeito brasileiro falando em inglês para que eles exprimam comentários sobre o que sentiram e pensaram ao ouvi-lo. Por fim, é solicitado que os estudantes caracterizem os sotaques dos sujeitos conforme alguns atributos bonito, padrão, familiar e difícil ou fácil de ser compreendido.

\section{ANÁLISE DE DADOS}

Iniciou-se a intervençâo explicando, brevemente, aos oito estudantes da turma, acerca da existência de falantes de inglês pelo mundo e os diferentes sotaques carregados por eles. Os alunos foram instruídos para que respondessem as perguntas 1 e 3 enquanto os áudios estavam sendo reproduzidos individualmente. Logo após, o áudio do brasileiro foi colocado para tocar enquanto eles teciam comentários na pergunta de número 5. Finalmente, repetiram-se as falas dos sujeitos com nacionalidade desconhecida para concluírem as respostas das questóes 2, 4 e 6.

É válido ressaltar que os alunos não tiveram conhecimento do país de origem dos falantes, com exceçẫo do brasileiro, uma vez que se pretendeu não influenciálos nas respostas que foram guiadas unicamente pelas percepçóes auditivas. Assim, eles referiram-se aos sujeitos por números, conforme a ordem em que os áudios estavam sendo reproduzidos. Dessa forma, o falante 1 equivale ao norte-americano, o falante 2 é o indiano, o falante 3 é o colombiano, o falante 4 é o africano e o falante 5 é o britânico.

De modo geral, pode-se dizer que todos os oito alunos tiveram dificuldade para identificar a nacionalidade dos falantes de inglês, todavia, um fato comum é que perceberam que o falante 1 e/ou 5 tratava-se de um estadunidense e/ou um britânico. Quanto aos outros três indivíduos, as observaçôes foram variadas e os comentários englobaram, em especial, o quanto as pronúncias das palavras eram 
diferentes, fato esse que foi imediatamente relacionado a um aprendiz de inglês, o que náo condiz com o perfil dos falantes. No entanto, apesar da complexidade, a compreensáo da fala náo foi ao todo afetada.

Imagem 2. Percepção de aluno acerca de falantes não-nativos.

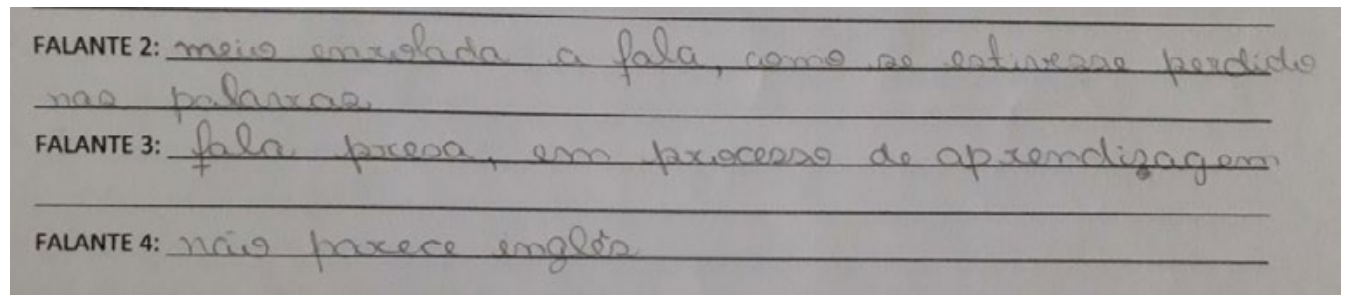

Fonte: acervo pessoal.

Imagem 3. Percepção de aluno acerca de falantes não-nativos.

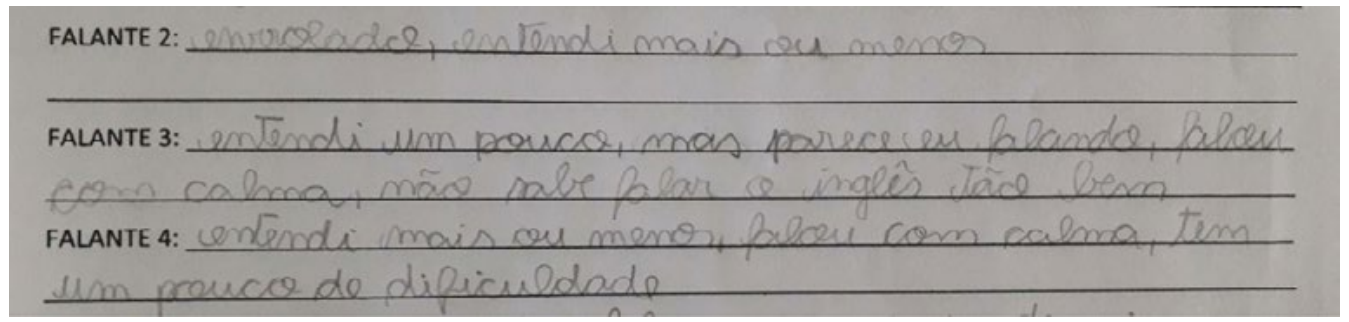

Fonte: acervo pessoal.

Imagem 4. Percepção de aluno acerca de falantes não-nativos.

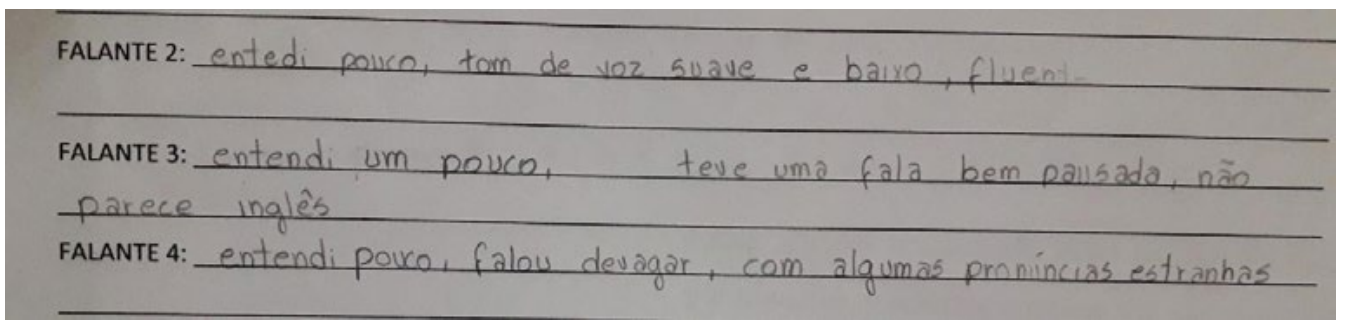

Fonte: acervo pessoal.

Dando sequência aos questionamentos, os alunos tiveram de escolher um dos sotaques dos falantes apresentados que eles gostariam de ter. Os falantes $5 \mathrm{e}$ 1 foram os preferidos, por serem considerados "mais natural" e por expressarem "menos dificuldade" e "mais domínio da língua". Além disso, um dos entrevistados classificou o sotaque do britânico como melhor, concordando com a falsa ideia popular de que existem variedades orais melhores e piores. 
Imagem 5. Preferência de aluno acerca do sotaque de inglês.

2. Qual dos sotaques de inglês você gostaria de falar? Por quê?

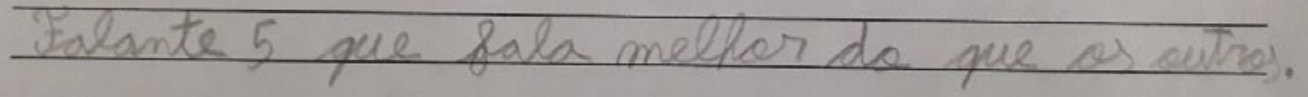

Fonte: acervo pessoal.

Imagem 6. Preferência de aluno acerca do sotaque de inglês.

2. Qual dos sotaques de inglês você gostaria de falar? Por quê?

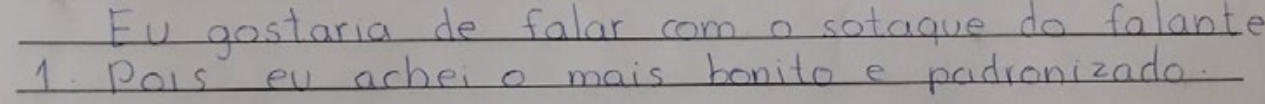

Fonte: acervo pessoal.

Assim como a resposta da gravura acima (imagem 6), os demais alunos também rotularam o falante 1 conforme os adjetivos bonito e padrão, juntamente do sujeito 5. Do mesmo modo, esses falantes foram considerados os mais fáceis de serem entendidos e cujos sotaques são mais parecidos com o deles. Tendo em vista que as aulas de língua inglesa da Escola de Idiomas frequentada pelos estudantes investigados são orientadas pela variedade norte-americana do inglês, possuindo materiais escritos, áudios e vídeos provenientes do país, não foi uma surpresa relacionarem suas vivências com a pronúncia de tais falantes.

Além das aulas de inglês semanais, os estudantes manifestaram que possuem mais contato com as variedades estadunidense e britânica (falantes 1 e 5) nos seus cotidianos. Eles foram capazes de identificar os mesmos dialetos de inglês em atividades exercidas nos momentos de lazer e passatempos na internet, através de vídeos no YouTube, filmes, seriados de TV, músicas e jogos. Essa resposta vai ao encontro da estatística que exibe que esses conteúdos, comumente consumidos pelos brasileiros, são provenientes de países hegemônicos como a Inglaterra e os Estados Unidos.

Imagem 7. Resposta de aluno sobre o contato com o inglês.

4. Com qual variedade/falante do inglês você tem mais contato? Quais os meios desse contato?

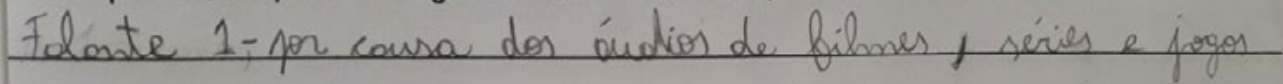

Fonte: acervo pessoal.

Finalmente, ao escutarem um brasileiro falando em inglês, os alunos sentiram maior tranquilidade para compreender o que estava sendo dito. Segundo seus relatos, 
o falante apresenta fluência no idioma, o que não os impediu de sentir familiaridade ao ouvi-lo. Ademais, um dos alunos ainda identificou uma proximidade com o inglês americano, corroborando com o princípio de que nós, brasileiros, temos os estadunidenses como o modelo de inglês e seguimos esse ideal ao exercermos nossa própria aprendizagem do idioma.

Imagem 8. Sentimento de aluno ao ouvir falante brasileiro.

5. Escute agora um falante brasileiro de inglês. $\mathrm{O}$ que você sente ao ouvi-lo?

Familiaridade, é como ouco amigos eprofessores falando.

Fonte: acervo pessoal.

Imagem 9. Sentimento de aluno ao ouvir falante brasileiro.

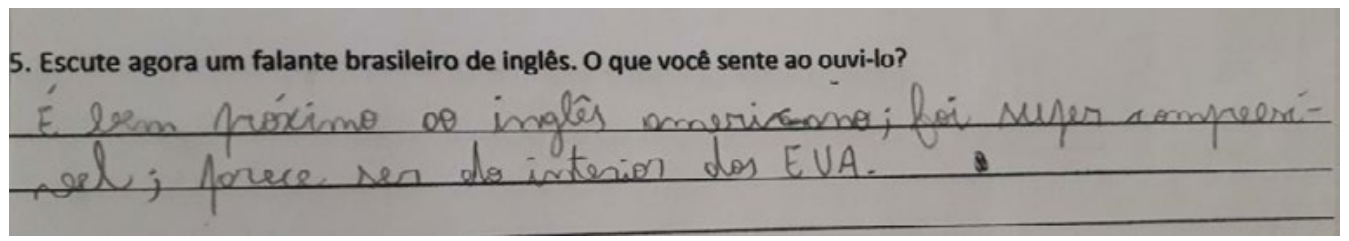

Fonte: acervo pessoal.

Após a aplicação da intervenção pedagógica e a revelação da nacionalidade dos falantes reproduzidos, os alunos reagiram positivamente à atividade realizada e comentaram desconhecer a existência de variedades orais táo distintas e únicas. Com isso, pode-se perceber que a presença nas esferas cotidianas de demais sotaques de inglês - que não sejam de países como Estados Unidos e Inglaterra - ainda é muito limitada. Da mesma forma, o ensino do idioma segue sendo centrado no falante nativo proveniente de tais países, impossibilitando que novos meios de aprendizagem da língua sejam propagados.

A julgar pela curiosidade dos estudantes investigados, nota-se que eles têm interesse em saber mais sobre falantes de inglês pelo mundo, inclusive aqueles que não o possuem como língua materna. Essa demanda só poderá ser oportunizada uma vez que as aulas de língua inglesa ofertarem um ensino intercultural de ILF, focado não em um modelo de falante a ser seguido, mas na valorização da diversidade de sociedades linguísticas e suas culturas.

\section{CONSIDERAÇÓES FINAIS}

O presente estudo teve por objetivo verificar as percepçóes de alunos de língua inglesa que frequentam o Ensino Médio e estão matriculados em uma Escola de Idiomas, perante as variedades linguísticas orais entre falantes do idioma residentes em países distintos. Para se ter acesso a esses dados, uma intervenção pedagógica foi 
planejada e aplicada e os resultados evidenciaram o êxito da pesquisa. Desse modo, os objetivos previamente expostos foram plenamente atingidos.

Apesar de o inglês estar se disseminando entre populaçóes dos mais diversos países, a nação soberana dos Estados Unidos, seguida pelo Reino Unido, continua sendo referência para muitos ao se tratar da língua inglesa. Como revelado na seção dos resultados, os aprendizes da língua costumam reproduzir padróes apresentados pelos falantes nativos norte-americanos e britânicos, não reconhecendo ou validando o inglês da Colômbia e da África do Sul, por exemplo.

As escolas brasileiras parecem não estar contribuindo para alterar essa perspectiva, uma vez que o ensino do idioma é comumente orientado pela pronúncia estadunidense. Faz-se necessária a mudança na mentalidade dos alunos, visto que "sustentar a predileção por modelos hegemônicos da língua inglesa no contexto educacional, especialmente em contextos como o Brasil, não representa a realidade vivida pelos aprendizes" (SILVA, 2019, p. 159). Uma educação que reconheça o inglês como língua franca, retire a responsabilidade dos alunos de seguir rótulos e retrate as diversidades culturais que falantes da língua carregam é crucial.

Almeja-se, com este trabalho, proporcionar reflexóes acerca do ensino de língua inglesa no Brasil e contribuir para uma nova formação de estudantes conscientes das variedades linguísticas e sociais. Investigaçóes como esta são de extrema importância, apesar de serem poucas, portanto, sugere-se que professores de língua façam pesquisas semelhantes para investigar o fenômeno em um locus de seu alcance e visem a incorporar novas práticas em sala de aula.

\section{REFERÊNCIAS}

ANJOS, Flávius Almeida dos. Ensinar e aprender inglês e a descentralização do falante nativo. In: Revista EntreLínguas, Araraquara, v. 5, n. 1, p. 57-62, jan./jun. 2019.

BRASIL. Base Nacional Comum Curricular. Brasília: MEC/Secretaria de Educação Básica, 2018.

CABRAL, Armanda. A importância do inglês no mundo atual. In: Revista PROFFORMA, Centro de Formação de Professores do Nordeste Alentejano, n. 13, jun. 2014.

GIMENEZ, T. et al. Inglês como língua franca: desenvolvimentos recentes. In: Revista Brasileira de Linguística Aplicada, Belo Horizonte, v. 15, n. 3, p. 593-619, jul./set. 2015.

JENKINS, Jennifer. The phonology of English as an international language. Oxford: Oxford University Press, 2000.

. English as a lingua franca: interpretations and attitudes. In: World Englishes, v. 28, n. 2 , p. 200-207, 2009. 
IDEA. International Dialects of English Archive. Disponível em: <https://www. dialectsarchive.com/>. Acesso em: 25 out. 2020.

LUSTIG, Robin. 2018. Can English remain the 'world's favourite' language?

Disponível em: <https:/www.bbc.com/news/world-44200901>. Acesso em: 08 out. 2020.

MESSIAS, Cinthia Maria da Fontoura. Um estudo sobre a variação linguística em língua inglesa. In: CLARABOIA, Jacarezinho, n.2/2, p. 217-233, jul./dez., 2015.

SILVA, Flavia Matias da. O ensino de língua inglesa sob uma perspectiva intercultural: caminhos e desafios. In: Trabalhos em Linguística Aplicada, Campinas, v. 58, n.1, jan./ apr. 2019.

UNIVERSIDADE FEDERAL DE SANTA MARIA - UFSM. Sociolinguística.

Disponível em: <https://repositorio.ufsm.br/bitstream/handle/1/16413/Curso_LetPortug-Lit_Sociolinguistica.pdf?sequence=1\&isAllowed=y>. Acesso em: 22 out. 2020.

WORLD POPULATION REVIEW. English Speaking Countries 2020. Disponível em: <https://worldpopulationreview.com/country-rankings/english-speaking-countries>. Acesso em: 08 out. 2020. 


\section{ANEXO A - HISTÓRIA “COMMA GETS A CURE”}

\section{COMMA GETS A CURE}

Well, here's a story for you: Sarah Perry was a veterinary nurse who had been working daily at an old zoo in a deserted district of the territory, so she was very happy to start a new job at a superb private practice in North Square near the Duke Street Tower. That area was much nearer for her and more to her liking. Even so, on her first morning, she felt stressed. She ate a bowl of porridge, checked herself in the mirror and washed her face in a hurry. Then she put on a plain yellow dress and a fleece jacket, picked up her kit and headed for work.

When she got there, there was a woman with a goose waiting for her. The woman gave Sarah an official letter from the vet. The letter implied that the animal could be suffering from a rare form of foot and mouth disease, which was surprising, because normally you would only expect to see it in a dog or a goat. Sarah was sentimental, so this made her feel sorry for the beautiful bird.

Before long, that itchy goose began to strut around the office like a lunatic, which made an unsanitary mess. The goose's owner, Mary Harrison, kept calling, "Comma, Comma," which Sarah thought was an odd choice for a name. Comma was strong and huge, so it would take some force to trap her, but Sarah had a different idea. First she tried gently stroking the goose's lower back with her palm, then singing a tune to her. Finally, she administered ether. Her efforts were not futile. In no time, the goose began to tire, so Sarah was able to hold onto Comma and give her a relaxing bath.

Once Sarah had managed to bathe the goose, she wiped her off with a cloth and laid her on her right side. Then Sarah confirmed the vet's diagnosis. Almost immediately, she remembered an effective treatment that required her to measure out a lot of medicine. Sarah warned that this course of treatment might be expensive - either five or six times the cost of penicillin. I can't imagine paying so much, but Mrs. Harrison-a millionaire lawyerthought it was a fair price for a cure. 


\section{ANEXO B - QUESTIONAMENTOS}

1. Escreva suas observações após ouvir cada um dos falantes.

FALANTE 1:

FALANTE 2:

FALANTE 3:

FALANTE 4:

FALANTE 5:

2. Qual dos sotaques de inglês você gostaria de falar? Por quê?

3. Você consegue identificar as nacionalidades dos falantes? Quais seriam? Como você identificou?

4. Com qual variedade/falante do inglês você tem mais contato? Quais os meios desse contato?

5. Escute agora um falante brasileiro de inglês. O que você sente ao ouvi-lo?

6. Qual dos falantes tem o sotaque mais...

bonito:

familiar:

padrão: difícil de entender:

fácil de entender:

parecido com o seu: 